\title{
Influence of Multi-Pass Hot Extrusion on Microstructure and Mechanical Properties of the Mg-4Zn-1.2Y-0.8Nd Alloy
}

\author{
Liyuan Sheng ${ }^{1,2, *} \mathbb{C}$, Xingru Zhang ${ }^{1}$, Hui Zhao ${ }^{3}$, Beining Du ${ }^{2}$, Yufeng Zheng ${ }^{1}$ and Tingfei $\mathrm{Xi}^{1}$ \\ 1 Shenzhen Institute, Peking University, Shenzhen 518057, China; zxr_hit@126.com (X.Z.); \\ yfzheng@pku.edu.cn (Y.Z.); w140933@pku.edu.cn (T.X.) \\ 2 PKU-HKUST Shenzhen-Hong Kong Institution, Shenzhen 518057, China; bndu10s@alum.imr.ac.cn \\ 3 School of Materials Science and Engineering, Xi'an Shiyou University, Xi'an 710065, China; \\ huier7921@126.com \\ * Correspondence: lysheng@yeah.net
}

check for updates

Citation: Sheng, L.; Zhang, X.; Zhao, H.; Du, B.; Zheng, Y.; Xi, T. Influence of Multi-Pass Hot Extrusion on Microstructure and Mechanical Properties of the $\mathrm{Mg}-4 \mathrm{Zn}-1.2 \mathrm{Y}-0.8 \mathrm{Nd}$ Alloy. Crystals 2021, 11, 425. https:// doi.org/10.3390/cryst11040425

Academic Editor: Pavel Lukáč

Received: 21 March 2021

Accepted: 13 April 2021

Published: 15 April 2021

Publisher's Note: MDPI stays neutral with regard to jurisdictional claims in published maps and institutional affiliations.

Copyright: (c) 2021 by the authors. Licensee MDPI, Basel, Switzerland. This article is an open access article distributed under the terms and conditions of the Creative Commons Attribution (CC BY) license (https:/ / creativecommons.org/licenses/by/ $4.0 /)$.

\begin{abstract}
In the present research, a Mg-4Zn-1.2Y-0.8Nd (wt.\%) alloy was heat treated and hot extruded with different passes. XRD, SEM, TEM and tensile testing were employed to characterize the microstructure evolution and mechanical properties. The results exhibited that the semi-continuously distributed $\mathrm{W}-\mathrm{Mg}_{3} \mathrm{Zn}_{3} \mathrm{Y}_{2}$ phases formed the skeleton structure which separated the $\alpha-\mathrm{Mg}$ matrix into a dual-size grain structure. In addition, the $\mathrm{Mg}_{24} \mathrm{Y}_{5}, \mathrm{Mg}_{41} \mathrm{Nd}_{5}$ and $\mathrm{Y}_{2} \mathrm{O}_{3}$ phase was also observed in the heat-treated alloy. Moreover, it was found that the Mg24Y5 phase had an orientation relationship with the $\alpha$-Mg matrix of $[111]_{\mathrm{Mg}_{24} \mathrm{Y} 5} / /[0001]_{\alpha-\mathrm{Mg}}$ and $(10 \overline{1})_{\mathrm{Mg}_{24} \mathrm{Y} 5} / /(10 \overline{10})_{\alpha-\mathrm{Mg}}$, and the $\mathrm{Mg}_{41} \mathrm{Nd}_{5}$ phase had an orientation relationship with the $\alpha-\mathrm{Mg}$ matrix of $[001]_{\mathrm{Mg} 41 \mathrm{Nd} 5} / /[0001]_{\alpha-\mathrm{Mg}}$. The one-pass hot extrusion segmented the secondary phases into small ones and refined the $\alpha-\mathrm{Mg}$ matrix. Due to the partly recrystallization and crystal orientation difference, the coarse elongated grain surrounded by fine recrystallized grain and secondary phase was the main feature of the one-pass hot extruded alloy. Furthermore, the secondary phases exhibited the linear distribution along the direction of hot extrusion. The two-pass hot extrusion refined the secondary phase and matrix further, which produced the ultrafine $\alpha$-Mg matrix with uniform grain size and a well redistributed secondary phase. Due to the microstructure optimization by the multi-pass hot extrusion, the ductility and strength of the $\mathrm{Mg}-\mathrm{Zn}-\mathrm{Y}-\mathrm{Nd}$ alloy were well improved, especially the two-pass hot extruded alloy which was significant improved in ductility and strength simultaneously.
\end{abstract}

Keywords: hot extrusion; $\mathrm{Mg}-\mathrm{Zn}-\mathrm{Y}-\mathrm{Nd}$ alloy; microstructure; mechanical properties

\section{Introduction}

Recently, Mg-based alloys have attracted much attention as one of most promising candidates for biomedical implants due to their high specific strength, low elastic modulus, relatively good biocompatibility and bio-absorbability [1-3]. However, the relative low ductility and strength of Mg-based alloys have severely impeded their medical applications. Therefore, it is necessary to enhance the mechanical properties of the Mg-based alloys before their application. Among all methods, alloying has been considered as a basic and convenient one. According to the previous research [4,5], the Zn doped Mg-based alloy has been considered the most potential candidate for biomedical implants, because of its relatively good balance between biocompatibility and mechanical properties. Previously, the study of Němec et al. [6] demonstrated that the $\mathrm{Mg}$ alloy with an appropriate $\mathrm{Zn}$ addition would obtain better mechanical properties and the $\mathrm{Mg}-12 \mathrm{Zn}$ (wt.\%) alloy prepared by equal-channel angular pressing possessed the best ductility and strength. The recent investigations [7-9] on Mg-Zn-based alloys exhibited that the introduction of rare earth elements $\mathrm{Y}$ and $\mathrm{Nd}$ could be helpful to refine the microstructure and increase mechanical properties. The research [8,9] on $\mathrm{Y}$ doped $\mathrm{Mg}-\mathrm{Zn}$-based alloy showed many kinds of phases such as the $\mathrm{W}$ phase $\left(\mathrm{Mg}_{3} \mathrm{Y}_{2} \mathrm{Zn}_{3}\right)$, I phase $\left(\mathrm{Mg}_{3} \mathrm{Zn}_{6} \mathrm{Y}\right)$ and long-period stacking 
ordered (LPSO) phase, which could enhance the strength of the alloy significantly. In addition, the study of $\mathrm{Zn}$ addition in $\mathrm{Mg}-\mathrm{Y}-\mathrm{Nd}$ alloy revealed that propriate $\mathrm{Zn}$ content could improve the strength and ductility simultaneously when its addition is less than 4 wt.\% [10].

Though the mechanical properties of the Mg alloy could be enhanced by the chemical composition modification, the relative coarse microstructure and secondary in the as-cast alloy were still detrimental to further improvement in mechanical properties, especially the ductility [9,10]. To solve these problems, Mg alloys always need further thermo-mechanical processing to refine the microstructure and precipitates [11,12]. Generally, hot extrusion and subsequent heat treatment has been considered as one of the most convenient and effective methods $[13,14]$. The recent research demonstrated that hot extrusion increased the mechanical properties of the $\mathrm{Mg}-5.1 \mathrm{Zn}-3.2 \mathrm{Y}-0.4 \mathrm{Zr}-0.4 \mathrm{Ca}$ alloy significantly in one pass, compared with the as-cast alloy [15], while the research on the cyclically extruded $\mathrm{Mg}-1.5 \mathrm{Zn}-0.25 \mathrm{Gd}$ alloy exhibited that the cyclic extrusion process could increase the mechanical properties obviously, but the strength is not linearly related with the cyclic times [16].

Based on the former research, it could be summarized that the Mg-Zn-based alloy with appropriate addition of $\mathrm{Y}$ and $\mathrm{Nd}$ would possess relatively good strength and ductility. Moreover, the subsequent hot extrusion would increase the mechanical properties of the alloy further by microstructure refinement. Therefore, in the present study, the designed alloy with a chemical composition of $\mathrm{Mg}-4 \mathrm{Zn}-1.2 \mathrm{Y}-0.8 \mathrm{Nd}$ (wt.\%, $\mathrm{Mg}-\mathrm{Zn}-\mathrm{Y}-\mathrm{Nd}$ for short) was prepared by a conventional metallurgical method and hot extrusion. The microstructure evolution and mechanical properties of the alloy during the multi-pass extrusion were investigated to explain the effect hot extrusion processing on deformation behavior.

\section{Materials and Methods}

The Mg-Zn-Y-Nd alloy with the chemical composition of $4 \% \mathrm{Zn}, 1.2 \% \mathrm{Y}, 0.8 \% \mathrm{Nd}$ and balanced $\mathrm{Mg}$ (wt.\%) was melted in an electric resistance furnace from pure $\mathrm{Mg}$, pure $\mathrm{Zn}$, $\mathrm{Mg}-25 \mathrm{Y}$ and $\mathrm{Mg}-25 \mathrm{Nd}$ master alloys under a $\mathrm{CO}_{2} / \mathrm{SF}_{6}$ (99:1) atmosphere. The chemical composition of the as-fabricated $\mathrm{Mg}-\mathrm{Zn}-\mathrm{Y}-\mathrm{Nd}$ alloy is shown in Table 1 . The melted alloy was held at $730{ }^{\circ} \mathrm{C}$ for $30 \mathrm{~min}$, then poured into a steel mold preheated to about $200{ }^{\circ} \mathrm{C}$ with a diameter of $150 \mathrm{~mm}$. The obtained as-cast billets were heat treated at $500{ }^{\circ} \mathrm{C}$ for $2 \mathrm{~h}$ and then surface machined to $\Phi 130 \mathrm{~mm}$ to remove the oxidized layer. Before the hot extrusion, the heat treated billets were preheated at $420 \pm 5{ }^{\circ} \mathrm{C}$ for $30 \mathrm{~min}$ to reach the extrusion temperature. During the hot extrusion, the billet was firstly hot extruded into a $\Phi 50-\mathrm{mm}$ rod at $400 \pm 5{ }^{\circ} \mathrm{C}$ to obtain the one-pass extrusion bar with the extrusion ratio of 6.76. The one-pass extrusion bar was cut into several pieces before the two-pass hot extrusion. After the preheat treatment, the one-pass extruded bar was hot extruded into a $\Phi 14-\mathrm{mm}$ rod at $400 \pm 5^{\circ} \mathrm{C}$ to obtain the two-pass extrusion bar with the extrusion ratio of 12.76. In all hot extrusion processing, the extrusion rate is about $8 \mathrm{~mm} / \mathrm{s}$.

Table 1. Chemical composition of the as-fabricated $\mathrm{Mg}-\mathrm{Zn}-\mathrm{Y}-\mathrm{Nd}$ alloy (wt. \%).

\begin{tabular}{cccc}
\hline $\mathbf{Z n}$ & $\mathbf{Y}$ & $\mathbf{N d}$ & $\mathbf{M g}$ \\
\hline 4.08 & 1.25 & 0.88 & Balanced \\
\hline
\end{tabular}

The specimens for phase and microstructure analysis were cut from the heat-treated alloy billet, one-pass extruded bar and two pass-extruded bars. They were ground using abrasive paper up to 2000 grit and then polished with diamond suspension from 3 to $0.5 \mu \mathrm{m}$. The specimen for microstructure observation was etched in acetic picral solution (5 mL acetic acid $+10 \mathrm{~mL}$ water $+5 \mathrm{~g}$ picric acid $+100 \mathrm{~mL}$ ethanol). The X-ray diffraction (XRD) analysis was performed on the Rigaku D/mac- 2400 with $\mathrm{Cu} \mathrm{K} \alpha$ radiation. The microstructure observation was carried out on the Phenom Pro scanning electron microscope (SEM) with the energy disperse spectroscopy (EDS). The JEM-2100 transmission electron microscope (TEM) operated at $200 \mathrm{kV}$ was used to perform the crystal structure 
characterization. The specimen for TEM was cut from the as-fabricated billet with the thickness of $0.4 \mathrm{~mm}$. Then, the specimen was polished to $25 \mu \mathrm{m}$ and shaped into $\varphi 3 \mathrm{~mm}$ in diameter followed by ion milling to perforation. The ion milling was carried out on the Gatan 691 ion thinner with the initial $4.5 \mathrm{kV}$ voltage and $6^{\circ}$ incident angle. With the processing of ion milling, the voltage and incident angle decrease gradually to $3 \mathrm{kV}$ and $3^{\circ}$. At the end, the specimen surface was cleaned with the voltage of $1.2 \mathrm{kV}$ and incident angle of $3^{\circ}$.

The tensile samples with a gauge size of $20 \mathrm{~mm} \times 4 \mathrm{~mm} \times 3 \mathrm{~mm}$ were cut from the heat treated and hot extruded alloys. Then, the samples were ground to 2000 grit abrasive paper before the tensile test. The uniaxial tensile test was performed on the SANS-CMT5105 testing machine with a speed of $0.1 \mathrm{~mm} / \mathrm{min}$ at room temperature to evaluate the mechanical properties. The tensile direction was parallel to the extrusion direction (ED). Three identical tensile tests were performed to evaluate tensile properties of the alloy with identical states. After the tensile test, the fracture surfaces of the failed specimens were observed by SEM.

\section{Results and Discussion}

\subsection{Microstructure}

The typical microstructure of the heat-treated $\mathrm{Mg}-\mathrm{Zn}-\mathrm{Y}-\mathrm{Nd}$ alloy is presented in Figure 1. It can be found that heat-treated alloy mainly contains $\alpha$-Mg and secondary phase, as shown in Figure 1a. The secondary phase could be divided into two kinds. One kind of secondary phase is large and mainly distributed along the grain boundary, which forms the skeleton structure. The other kind of secondary phase is small and mainly distributed inside the grains. Moreover, the matrix also has a dual-size grain structure. It seems that the coarse secondary phase prefers to form along the small grain boundary. Based on the previous research $[17,18]$, these secondary phases and precipitates in the $\mathrm{Mg}-\mathrm{Zn}-\mathrm{Y}-\mathrm{Nd}$ alloy should be mainly $\mathrm{W}-\mathrm{Mg}_{3} \mathrm{Zn}_{3} \mathrm{Y}_{2}$ phase or $\mathrm{I}-\mathrm{Mg}_{3} \mathrm{Zn}_{6} \mathrm{Y}$ phase. Moreover, the $\mathrm{Zn} /(\mathrm{Y}+\mathrm{Nd})$ ratio could be used to distinguish the $\mathrm{W}$ phase and I phase. In the present study, the $\mathrm{Zn} /(\mathrm{Y}+\mathrm{Nd})$ ratio of the nominal alloy composition is less than two, as shown in Figure $1 \mathrm{~b}$. Considering the influence of solid solute $\mathrm{Zn}$ in matrix, the $\mathrm{Zn} /(\mathrm{Y}+\mathrm{Nd})$ ratio of the secondary phase is be much lower than two, so the secondary phase is more likely to be $\mathrm{W}-\mathrm{Mg}_{3} \mathrm{Zn}_{3} \mathrm{Y}_{2}$.

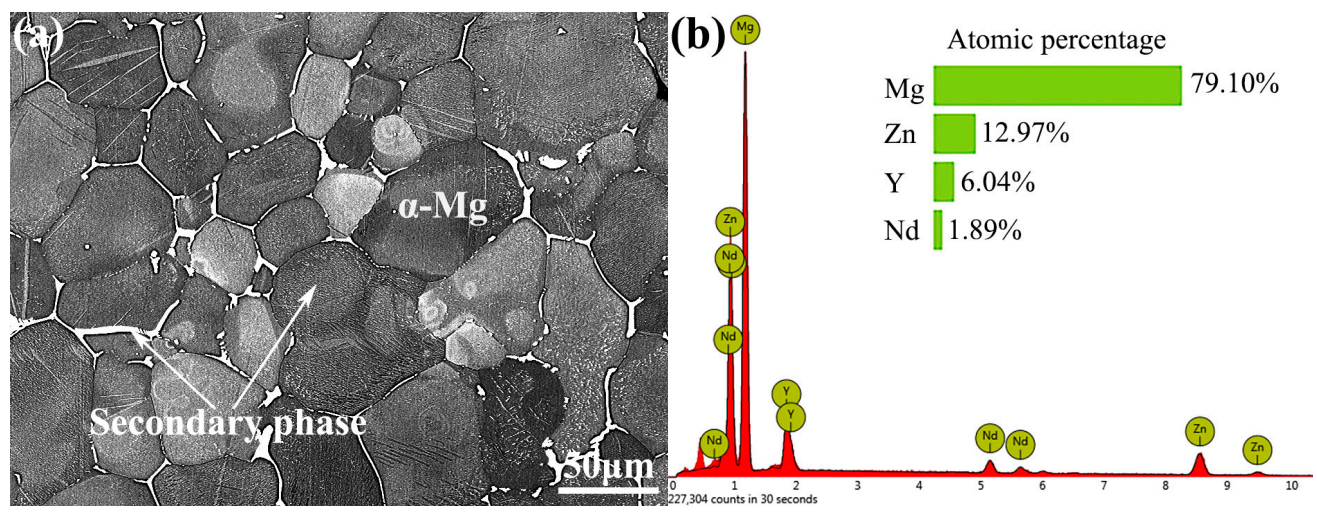

Figure 1. SEM micrograph of the heat-treated $\mathrm{Mg}-\mathrm{Zn}-\mathrm{Y}-\mathrm{Nd}$ alloy (a) and EDS spectrum of the secondary phase (b).

To confirm the phase constituent in the heat-treated $\mathrm{Mg}-\mathrm{Zn}-\mathrm{Y}-\mathrm{Nd}$ alloy, $\mathrm{XRD}$ analysis was carried out and the result is shown in Figure 2. Clearly, there are mainly two phases. One is the $\alpha-\mathrm{Mg}$ which exhibits random crystal orientations; the other is the $\mathrm{W}-\mathrm{Mg}_{3} \mathrm{Zn}_{3} \mathrm{Y}_{2}$ phase which exhibits strong crystal preference along (220). Moreover, there are still some small diffraction peaks which seem to be the $\mathrm{Mg}_{24} \mathrm{Y}_{5}$ phase and $\mathrm{Mg}_{41} \mathrm{Nd}_{5}$ phase. 


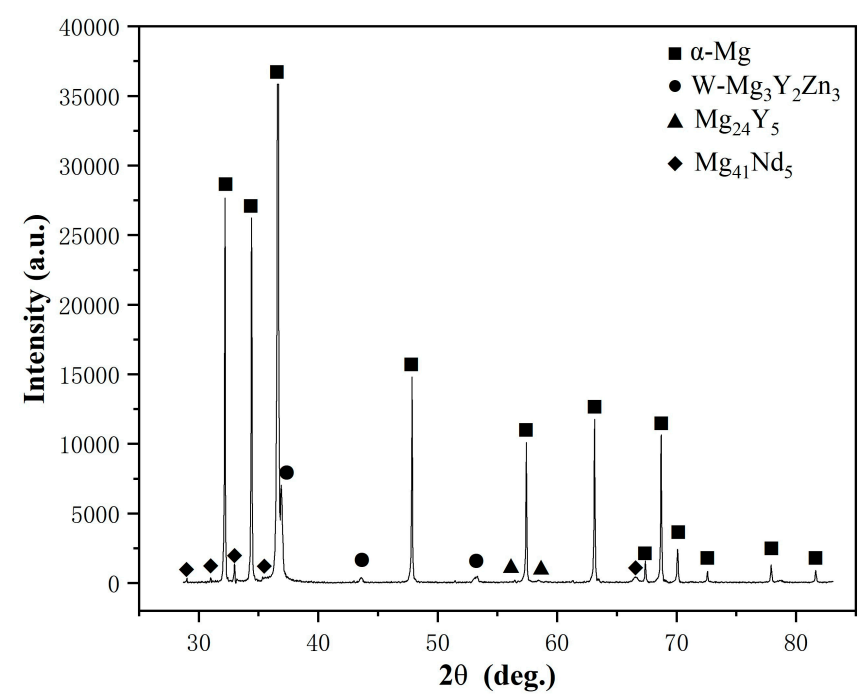

Figure 2. XRD pattern of the heat-treated $\mathrm{Mg}-\mathrm{Zn}-\mathrm{Y}-\mathrm{Nd}$ alloy.

TEM observations on the heat-treated $\mathrm{Mg}-\mathrm{Zn}-\mathrm{Y}-\mathrm{Nd}$ alloy reveal that the coarse secondary phase along grain boundary is the $\mathrm{Mg}_{3} \mathrm{Y}_{2} \mathrm{Zn}_{3}$ phase, as shown in Figure $3 \mathrm{a}$. The inset selected area electron diffraction (SAED) pattern confirms the formed $\mathrm{Mg}_{3} \mathrm{Y}_{2} \mathrm{Zn}_{3}$ phase with the space group of Fm $3 \mathrm{~m}$ and the face-centered cubic crystal lattice with a lattice constant of $\mathrm{a}=\mathrm{b}=\mathrm{c}=0.6833 \mathrm{~nm}$. The further characterization on precipitates inside the grain exhibits that some of them are the $\mathrm{Mg}_{24} \mathrm{Y}_{5}$ phase, as shown in Figure $3 \mathrm{~b}$. Combining with the inset SAED pattern, it can be determined that the $\mathrm{Mg}_{24} \mathrm{Y}_{5}$ phase has the space group of I-43m and body-centered cubic crystal lattice the with lattice constant of $\mathrm{a}=\mathrm{b}=\mathrm{c}=1.1204 \mathrm{~nm}$. In addition, the SAED pattern also reveals that the $\mathrm{Mg}_{24} \mathrm{Y}_{5}$ phase has orientation relationships with the $\alpha-\mathrm{Mg}$ matrix, which can be described as $[111]_{\mathrm{Mg} 24 \mathrm{Y} 5} / /[0001]_{\alpha-\mathrm{Mg}}$ and $(10 \overline{1})_{\mathrm{Mg} 24 \mathrm{Y} 5} / /(10 \overline{1} 0)_{\alpha-\mathrm{Mg}}$. Such orientation relationships agree with the previous research [19]. In addition, the $\mathrm{Mg}_{24} \mathrm{Y}_{5}$ phases in the grain have different sizes. One is about ten nanometers and the other is about several nanometers. The TEM observation on the grain boundary also shows the $\mathrm{Mg}_{41} \mathrm{Nd}_{5}$ precipitate which has the space group of $\mathrm{I} 4 / \mathrm{m}$ and the tetragonal crystal lattice with a lattice constant of $\mathrm{a}=\mathrm{b}=1.476 \mathrm{~nm}$ and $\mathrm{c}=1.039 \mathrm{~nm}$, as shown in Figure 3c. Moreover, the SAED pattern also reveals that the $\mathrm{Mg}_{41} \mathrm{Nd}_{5}$ precipitate has an orientation relationship with the $\alpha-\mathrm{Mg}$ matrix, which can be described as $[001]_{\mathrm{Mg} 41 \mathrm{Nd} 5} / /[0001]_{\alpha-\mathrm{Mg}}$. Further observations revealed that there are some small particles, as shown in Figure 3d. Combining with the SAED pattern, it can be confirmed as the $\mathrm{Y}_{2} \mathrm{O}_{3}$ phase which has a primitive cubic crystal lattice and a space group of Ia3 with a lattice constant of $\mathrm{a}=\mathrm{b}=\mathrm{c}=1.0604 \mathrm{~nm}$. According to the previous research $[20,21]$, the casting alloy would always be accompanied with oxidation, which is demonstrated as the oxide particle or oxidation film. In the present study, the activity of the $\mathrm{Mg}$ would inevitably involve oxygen, which is able to react with the rare earth element during the metallurgy and casting process. The formation of this kind of $\mathrm{Y}_{2} \mathrm{O}_{3}$ is beneficial to the grain boundary strength by capturing impurities and decontamination of the boundary. 

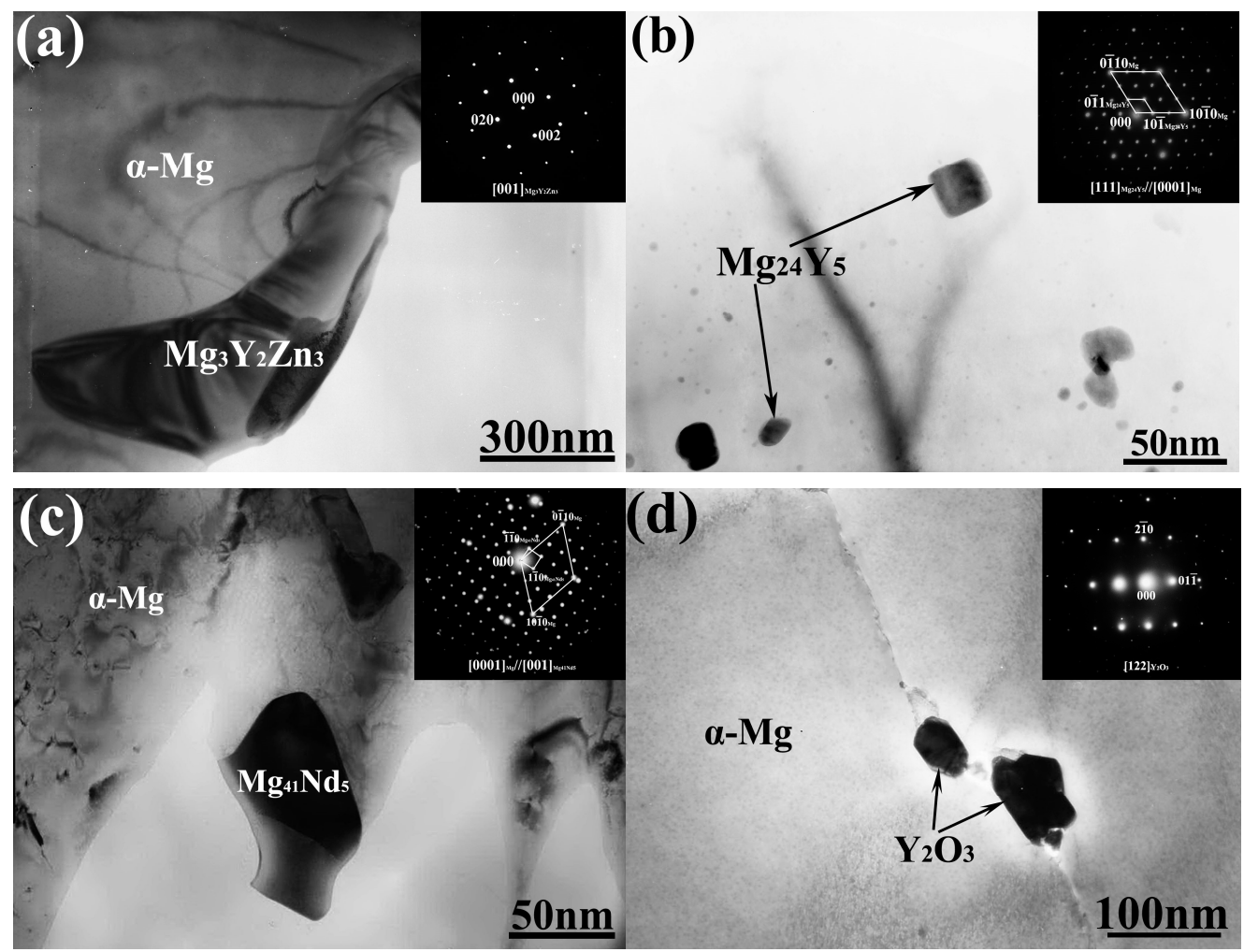

Figure 3. Bright-field TEM micrograph of the precipitates in the Mg-Zn-Y-Nd alloy: (a) the $\mathrm{Mg}_{3} \mathrm{Zn}_{3} \mathrm{Y}_{2}$ phase along grain boundary, (b) the small $\mathrm{Mg}_{24} \mathrm{Y}_{5}$ particles randomly distributed in the matrix, (c) the $\mathrm{Mg}_{41} \mathrm{Nd}_{5}$ precipitate along the boundary, (d) morphology of the $\mathrm{Y}_{2} \mathrm{O}_{3}$ particle along the grain boundary (inset micrographs exhibiting the corresponding selected area electron diffraction (SAED) patterns of the phases).

The typical microstructure of the $\mathrm{Mg}-\mathrm{Zn}-\mathrm{Y}-\mathrm{Nd}$ alloy with one-pass hot extrusion is exhibited in Figure 4. The cross-sectional microstructure of the one-pass extruded alloy shows a dual-size grain structure in which the coarse grains are surrounded by the small grains, as shown in Figure 4a. The coarse secondary phase has been broken into a small one which is semi-continuously distributed along the elongated grain boundary. Moreover, the precipitates inside the grain become fine and are distributed uniformly. The longitudinal-sectional microstructure of the one-pass extruded alloy demonstrates that the coarse grain should be the elongate grain and the small grain should be the crystallized grain, as shown in Figure $4 \mathrm{~b}$. Comparing with the heat-treated alloy, the hot extrusion has refined the microstructure of the alloy obviously. Based on the recent research [21,22], during the hot extrusion processing, the extrusion would compel the grains to deform compatibly along certain direction, which inevitably results in the grain twist to reach the favorable crystallographic directions and planes for slip movement. Then, the region adjacent to the grain boundary would experience deformation firstly. The piling up dislocations along grain boundary could lead to the formation of low-angle grain boundaries and subgrains with the help of high processing temperature [23,24]. Due to the crystal orientation difference of the original grains, some grains have to experience more twist before they reach the favorable crystallographic directions and planes for slip movement. Therefore, there are obvious differences between the grains after hot extrusion. Some original grains with crystallographic directions and planes apt for slip movement are elongated easily, while the others experience greater deformation and more recrystallization. Therefore, it can be found that some regions are almost full of recrystallized grains and some regions mainly contain the elongated grains. Moreover, the relatively small extrusion ratio and short extrusion time in the one-pass extrusion also contribute to the bimodal microstructure. 


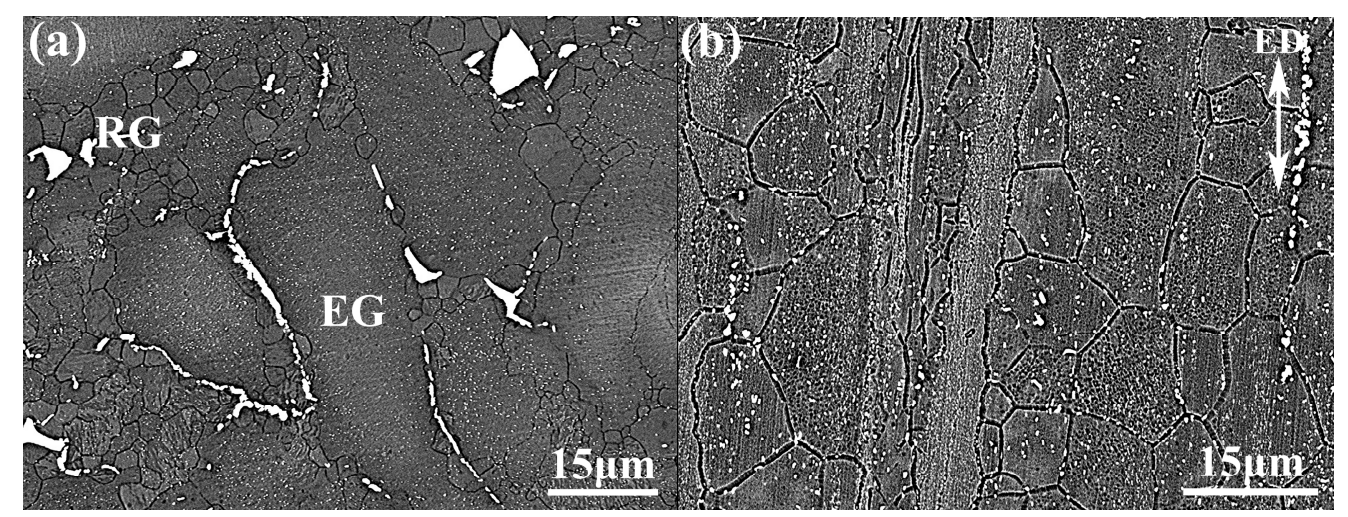

Figure 4. SEM micrograph of the Mg-Zn-Y-Nd alloy with one-pass hot extrusion: (a) cross-sectional microstructure showing the dual-size grain structure, (b) longitudinal-sectional microstructure showing the elongated grain structure (RG: recrystallized grain, EG: elongated grain).

The XRD analysis on the Mg-Zn-Y-Nd alloy with one-pass hot extrusion was carried out and the results are given in Figure 5. It can be found that the cross section of the one-pass hot extruded alloy demonstrates ultra-strong crystal orientation preference along the $(10 \overline{1} 0)$, as shown in Figure 5a. However, the longitudinal section of the one-pass hot extruded alloy exhibits relative random crystal orientation, as shown in Figure $5 \mathrm{~b}$. Compared with the XRD pattern of heat-treated alloy, the one-pass hot extrusion obviously resulted in the crystal orientation evolution. It promotes the $\alpha$-Mg grains to arrange their $\{10 \overline{1} 0\}$ crystal plane perpendicular to the extrusion direction. The strong diffraction

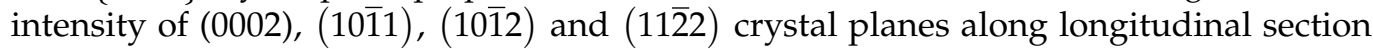
also indicates that hot extrusion promotes the grain twist to increase its deformability, because the crystal orientation preference would benefit the start of the basal, prismatic and pyramidal slip system during the deformation. In addition, the relative random crystal orientation also reflects the uncompleted recrystallization processing during one-pass hot extrusion.
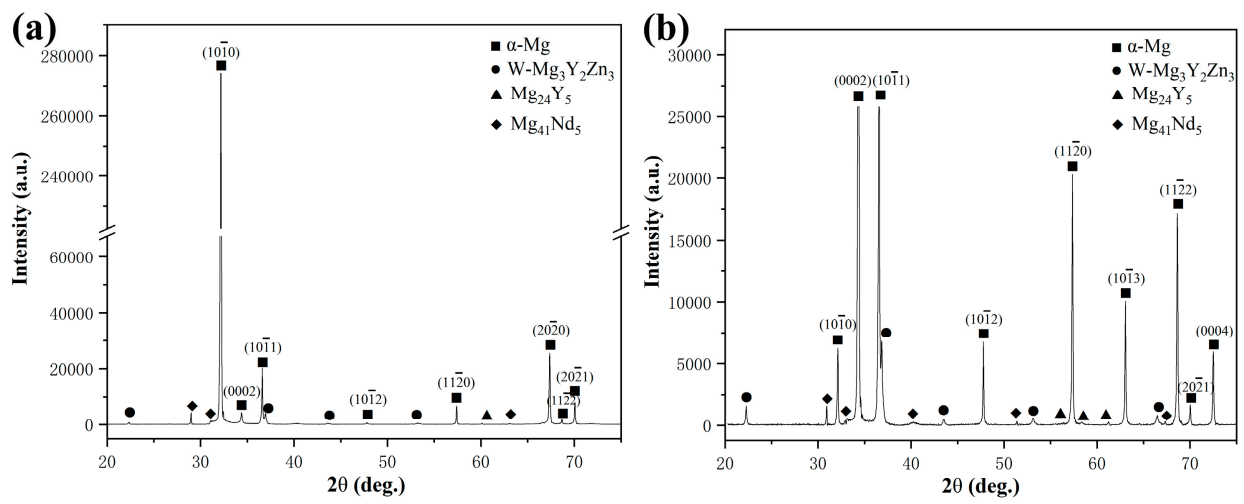

Figure 5. XRD patterns of the Mg-Zn-Y-Nd alloy with one-pass hot extrusion: (a) cross section of the extrude alloy (perpendicular to the extrusion direction), (b) longitudinal section of the extruded alloy (parallel to the extrusion direction).

The typical SEM micrographs of the Mg-Zn-Y-Nd alloy with two-pass hot extrusion are shown in Figure 6. Clearly, the two-pass extrusion has refined the grain significantly. The cross-sectional microstructure of the two-pass hot extruded alloy exhibits the ultrafine grain with average size of about $4 \mu \mathrm{m}$, as shown in Figure 6a. Except for the ultrafine grain, the two-pass hot extrusions also optimize the secondary phase by uniform redistribution and size refinement. The longitudinal-sectional microstructure of the two-pass hot extruded alloy shows that the gray structures are the grains elongated along the extrusion direction, as shown in Figure 6b. In addition, most of the gray structures are parallel to 
each other with thickness from 3 to $7 \mu \mathrm{m}$. Such a structure might be inherited from the elongated grain in the one-pass extruded alloy. Compared with the one-pass extruded alloy, the secondary phases along the grain boundary become finer and tend to be spheroidizing. Different from the uniformly distribution on cross section, the secondary phases still linearly distribute along the extrusion direction in the longitudinal section and they mainly locate in the region of recrystallized grains.

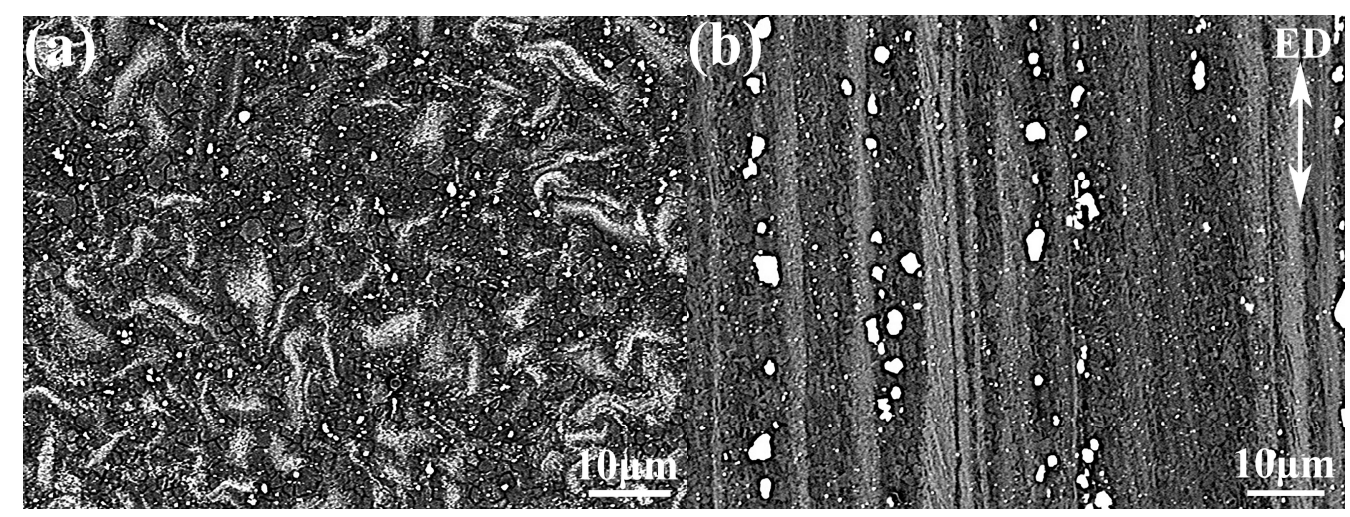

Figure 6. SEM micrograph of the Mg-Zn-Y-Nd alloy with two-pass hot extrusion: (a) cross-sectional microstructure showing the ultrafine grains, (b) longitudinal-sectional microstructure showing the paralleled elongated grains and linearly distributed secondary phase.

XRD analysis on the Mg-Zn-Y-Nd alloy with two-pass hot extrusion was performed and the results are given in Figure 7 . The cross-sectional XRD pattern reveals that the alloy shows the strongest diffraction peak at (1010), as shown in Figure 7a. While the XRD pattern of the longitudinal section shows that it possesses the strongest diffraction peak at (0002), as shown in Figure 7b. Compared with the one-pass hot extruded alloy, the diffraction peaks at $(10 \overline{1} 1),(1 \overline{1} 20)$ and $(11 \overline{2} 2)$ were obviously weakened. Based on the microstructure observation, it can be deduced that the recrystallization results in such an evolution of crystal orientation. Based on the previous research [25], the preference of the $\{10 \overline{1} 0\}$ crystal plane of the $\mathrm{Mg}$ grain perpendicular to the extrusion direction could benefit the initiation of a basal slip system. The $\{10 \overline{1} 1\},\{10 \overline{1} 2\}$ and $\{11 \overline{2} 2\}$ crystal planes of the $\alpha$-Mg grain paralleled to the extrusion direction would benefit the initiation of a cone slip system. Due to the lowest critical resolved shear stress for initiation of basal slip system occurring, the evolution of crystal orientation during the hot extrusion increases the deformability of the alloy. Compared with one-pass hot extrusion, two-pass hot extrusion improves the deformability of the alloy obviously, because more $\mathrm{Mg}$ grains are able to initiate the basal slip system. 

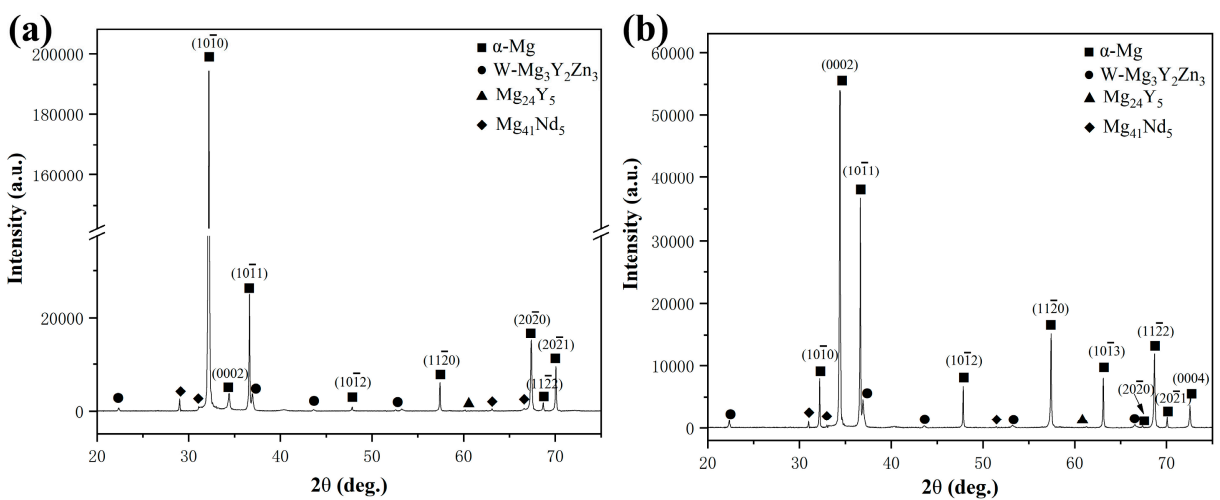

Figure 7. XRD patterns of the Mg-Zn-Y-Nd alloy with two-pass hot extrusion: (a) cross section of the extrude alloy (perpendicular to the extrusion direction), (b) longitudinal section of the extruded alloy (parallel to the extrusion direction).

TEM observations were performed on the $\mathrm{Mg}-\mathrm{Zn}-\mathrm{Y}-\mathrm{Nd}$ alloys with one-pass and two-pass extrusion and the results are exhibited in Figure 8. It can be seen that one-pass hot extrusion resulted in great deformation in the secondary phase and matrix, as shown in Figure 8a. The secondary phases have broken into small ones with irregular shape and most of them exhibit linearly distributing morphology. Moreover, there are some phases with near spherical shape are distributed in the matrix, which is separated by the linearly distributed secondary phases. Such morphology of the secondary phase contributes to the recrystallization and grain refinement [26]. Additionally, the linearly distributed secondary phases act as the grid which refines the matrix into ultrafine grains. The TEM observations on the two-pass hot extruded alloy demonstrate that there are small particles along grain boundaries, as shown in Figure 8b. Based on the morphology, most of the particles along the grain boundary should be precipitates which form during the two-pass hot extrusion processing. According to the previous research [27], the $Y$ would have more than $6 \mathrm{wt} . \%$ solid solubility in $\mathrm{Mg}$ at temperatures above $400{ }^{\circ} \mathrm{C}$. Then, the heat treatment before the hot extrusion would promote the solid solution of the alloying element and the subsequent precipitation during the hot extrusion. In addition, the boundary, substructure and crystal defect would provide the site for nucleation of precipitates. Therefore, it can be seen that there are some new small diffraction peaks in the XRD patterns of the hot extruded alloy, compared with the heat-treated alloy.
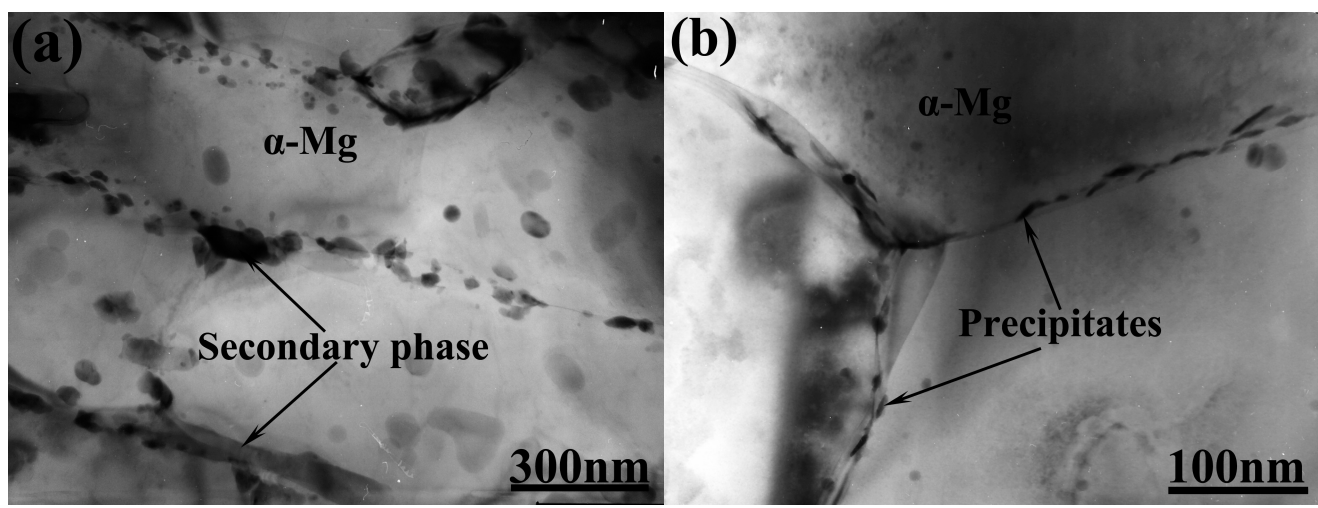

Figure 8. Bright-field TEM micrograph of the precipitate and phase in the hot extruded $\mathrm{Mg}-\mathrm{Zn}-$ Y-Nd alloy: (a) morphology of the precipitates array along the extrusion direction in the one-pass hot extruded alloy, (b) morphology of the precipitates along grain boundaries in the two-pass hot extruded alloy. 


\subsection{Mechanical Properties}

The tensile true stress-true strain curves and mechanical properties of the heat treated and hot extruded $\mathrm{Mg}-\mathrm{Zn}-\mathrm{Y}-\mathrm{Nd}$ alloys are shown in Figure 9. It can be found that the $\mathrm{Mg}-\mathrm{Zn}-\mathrm{Y}-\mathrm{Nd}$ alloys with different states almost exhibit similar tendency in that the plastic deformation is after the yielding, as shown in Figure 9a. However, the $\mathrm{Mg}-\mathrm{Zn}-\mathrm{Y}-\mathrm{Nd}$ alloys with different states demonstrate different plastic deformation behaviors. The heattreated $\mathrm{Mg}-\mathrm{Zn}-\mathrm{Y}-\mathrm{Nd}$ alloy exhibits continuous work hardening with the stress obviously increasing. For the $\mathrm{Mg}-\mathrm{Zn}-\mathrm{Y}-\mathrm{Nd}$ alloy with one-pass extrusion, its stress increases slowly and there is a jump at the half stage of plastic deformation. While the $\mathrm{Mg}-\mathrm{Zn}-\mathrm{Y}-\mathrm{Nd}$ alloy with two-pass extrusion almost has no increase in stress after yielding. The detailed mechanical properties indicate that the extrusion process has improved the strength and ductility of the alloy obviously, as shown in Figure $9 \mathrm{~b}$ and Table 2. The elongation (E), yield strength (YS) and ultimate tensile strength (UTS) of the heat-treated alloy are $9.5 \%, 105 \mathrm{MPa}$ and $230 \mathrm{MPa}$, respectively. With the one-pass extrusion processing, the alloy obtains the $\mathrm{E}$, YS and UTS of 9\%, $225 \mathrm{MPa}$ and $295 \mathrm{MPa}$, respectively. Compared with the heat-treated alloy, the one-pass hot extrusion enhanced the YS and UTS of the alloy by about $115 \%$ and $30 \%$, but the EL decreased a little. After the two-pass hot extrusion, the elongation, YS and UTS of the alloy reached $17.5 \%, 300 \mathrm{MPa}$ and $330 \mathrm{MPa}$, respectively. Compared with the heat-treated alloy, the two-pass hot extrusion processing increased the E, YS and UTS by about $85 \%, 180 \%$ and $45 \%$, respectively. Different from the one-pass hot extrusion, the two-pass hot extrusion greatly improved the ductility and strength simultaneously. Such an improvement should be ascribed to the microstructure optimization. The fine grain and secondary phase should be the main factors that influence the strength and ductility. Combining with the microstructure observation, it could be concluded that the strength improvement of the one-pass hot extruded alloy should be mainly ascribed to the partly refined grain and secondary phase. However, the relative coarse elongated grain and semi-continuously distributed secondary phase also are detrimental to the ductility. The two-pass hot extrusion thoroughly refines the grains and redistributes the secondary phase uniformly. Therefore, the alloy with two-pass hot extrusion obtains great improvement in strength and ductility.
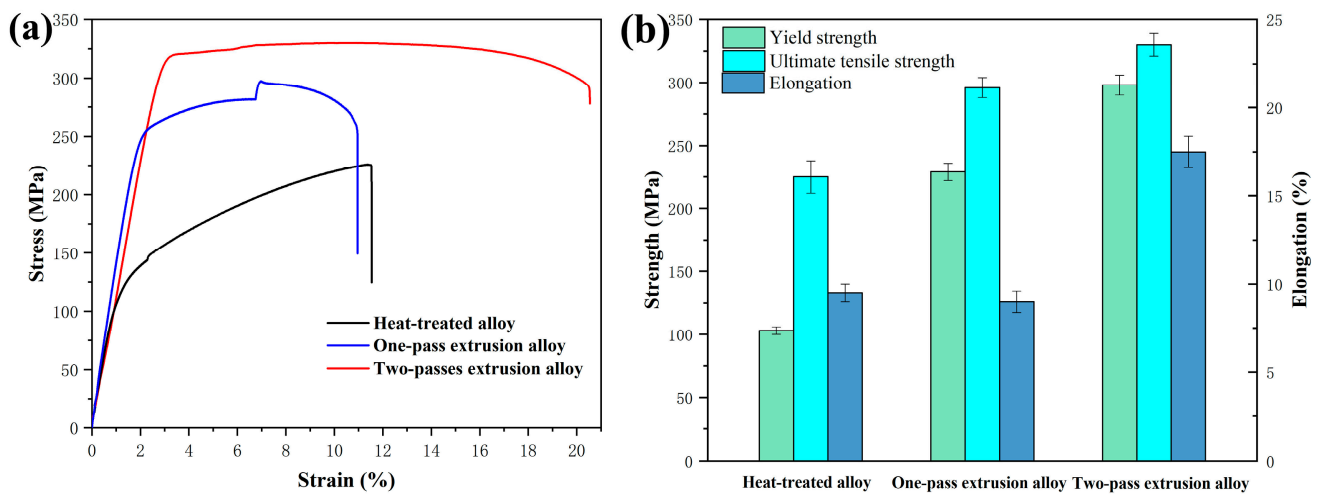

Figure 9. (a) Tensile true stress-true strain curves of the $\mathrm{Mg}-\mathrm{Zn}-\mathrm{Y}-\mathrm{Nd}$ alloys with different states, (b) variation of mechanical properties of the $\mathrm{Mg}-\mathrm{Zn}-\mathrm{Y}-\mathrm{Nd}$ alloys with different states.

Table 2. The detailed mechanical properties of the $\mathrm{Mg}-\mathrm{Zn}-\mathrm{Y}-\mathrm{Nd}$ alloys with different states.

\begin{tabular}{cccc}
\hline & YS (MPa) & UTS (MPa) & E (\%) \\
\hline Heat-treated alloy & 105 & 225 & 9.5 \\
One-pass extrusion alloy & 230 & 295 & 9.0 \\
Two-pass extrusion alloy & 300 & 330 & 17.5 \\
\hline
\end{tabular}

To further explain the variation of the mechanical properties with the processing, the observations on the fracture surface of $\mathrm{Mg}-\mathrm{Zn}-\mathrm{Y}-\mathrm{Nd}$ alloy were performed and the results 
are shown in Figure 10. It can be found that the fracture surface of the heat-treated alloy contains some cleavage facets and debonding features, as shown in Figure 10a. Combining with the microstructure observation, the debonding should be formed along the coarse secondary phase interface and the cleavage should be result of the crack rapidly propagated in the coarse $\alpha-\mathrm{Mg}$ grain. These brittle fracture behaviors would obviously influence the mechanical properties. The one-pass hot extruded alloy demonstrates a relative flat fracture surface with small cleavage facets, as shown in Figure 10b. Compared with the heat-treated alloy, the one-pass hot extrusion just changes the cleavage facet from a big one into small one, and the brittle fracture still plays a similar role. Then, it can be understood why the heated alloy and one-pass hot extruded alloy almost have the same elongation. Different from the heat-treated alloy and one-pass hot extruded alloy, the two-pass hot extrusion has changed the fracture of the alloy to ductile mode. The dimple is the main characteristic of the fracture surface, as shown in Figure 10c. Therefore, the $\mathrm{Mg}-\mathrm{Zn}-\mathrm{Y}-\mathrm{Nd}$ alloy with two-pass hot extrusion possesses the best ductility of all the alloys.
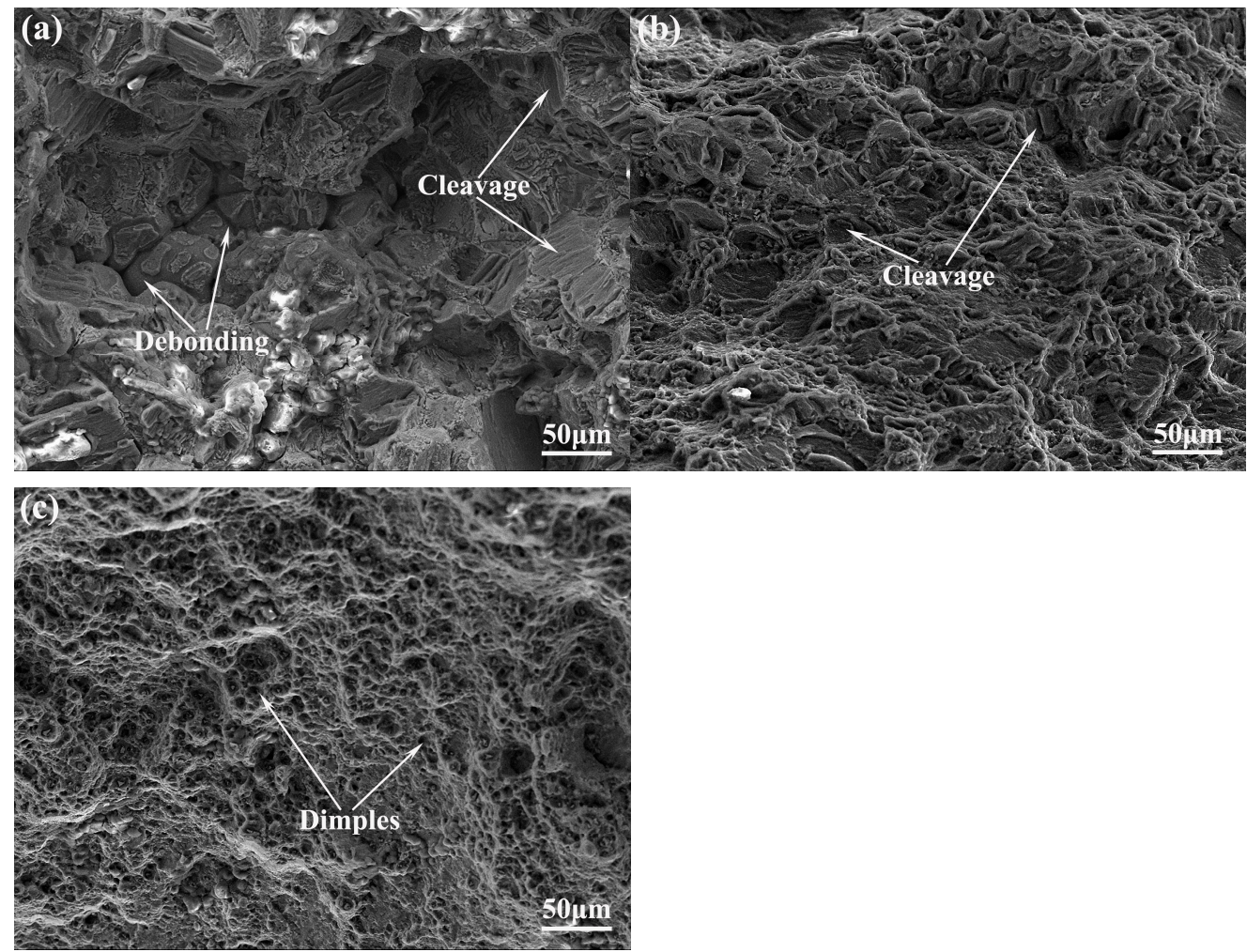

Figure 10. Fracture surface of the $\mathrm{Mg}-\mathrm{Zn}-\mathrm{Y}-\mathrm{Nd}$ alloy with different processing: (a) heat treatment, (b) one-pass hot extrusion, (c) two-pass hot extrusion.

The observations on the longitudinal sections of the tensile specimens with different processing are exhibited in Figure 11. Clearly, the hot extrusion changed the crack initiation and propagation. For the heat-treated alloy, the crack mainly propagates along grain boundaries, as shown in Figure 11a. Such a feature should be ascribed to the existence of coarse secondary phase which would be the preference of crack initiation and propagation, because the great difference of the crystal lattice and deformability between the $\alpha-\mathrm{Mg}$ and $\mathrm{W}-\mathrm{Mg}_{3} \mathrm{Zn}_{3} \mathrm{Y}_{2}$ phases would result in the dislocation piling up and stress concentration here. In addition, it is difficult for the coarse $\alpha-\mathrm{Mg}$ grain to coordinate the deformation. Therefore, the crack propagating along the secondary phase interface or through the grain produces the debonding and cleavage facet. Though the one-pass hot extrusion partly refined the matrix, the elongated grains also obviously influence the deformation. As shown in Figure 11b, the one-pass hot extruded alloy contains a lot of twins in the elongated grain after the tensile test. Moreover, the cracks could be observed along the 
twin boundary and secondary phase interface. Therefore, it can be deduced that the once the crack propagated along the twin boundary it traversed the refined grains region rapidly. Then, the crystallized fine grain plays no effect on the ductility of the alloy. After the twopass hot extrusion, the alloy exhibits different morphology with a zigzag shape fracture and no twinning in the matrix, as shown in Figure 11c. Such a feature indicates that the alloy could take full use of the coordination deformability of the ultrafine grain. Combining with the well redistributed fine secondary phases, the two-pass hot extruded alloy obtains the best ductility and strength.
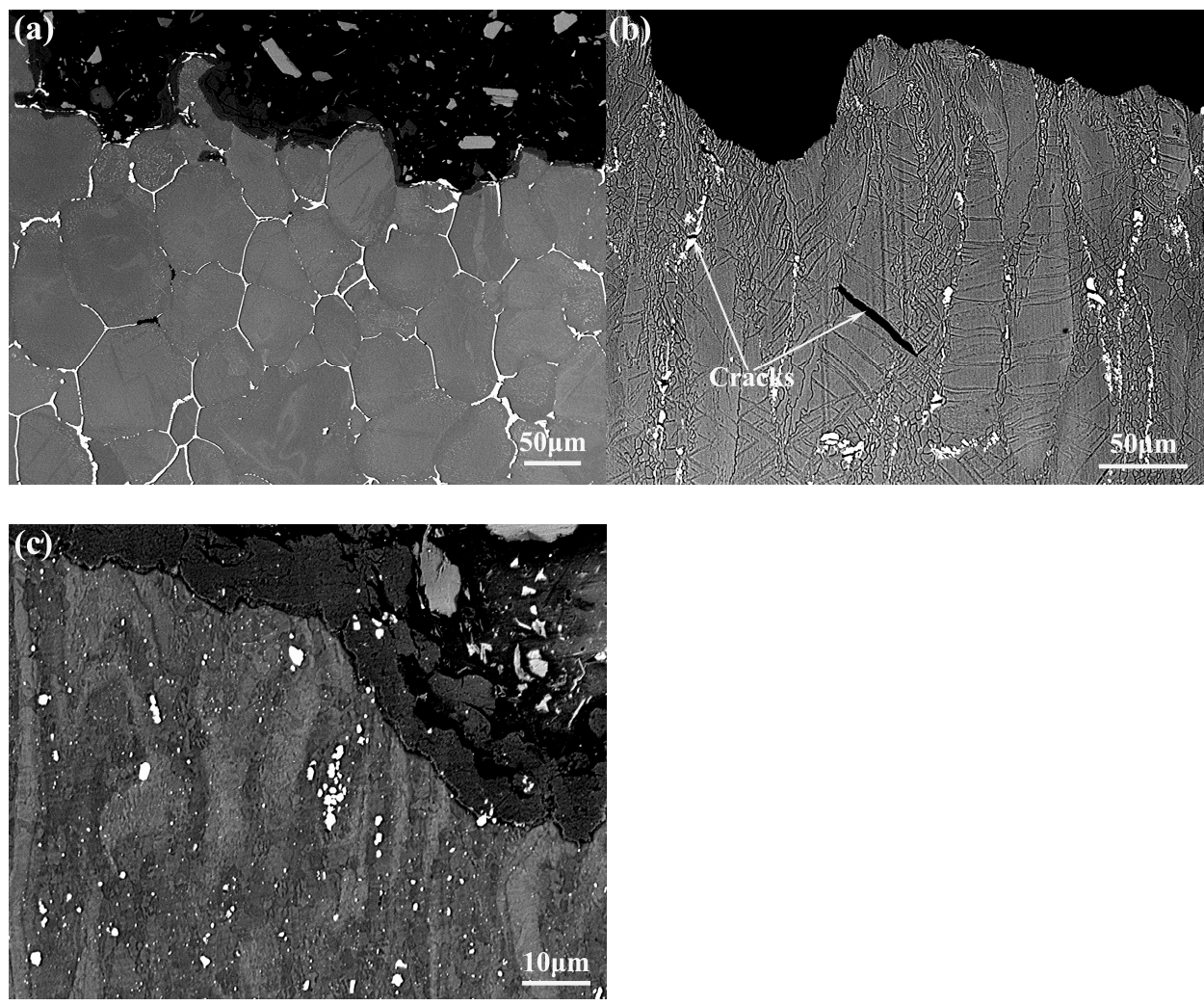

Figure 11. Longitudinal-sectional microstructure of the tensile failed $\mathrm{Mg}-\mathrm{Zn}-\mathrm{Y}-\mathrm{Nd}$ alloy with different processing: (a) heat treatment, (b) one-pass hot extrusion, (c) two-pass hot extrusion.

Based on the microstructure evolution and mechanical properties of the $\mathrm{Mg}-\mathrm{Zn}-\mathrm{Y}-$ $\mathrm{Nd}$ alloy with different states, the main effect of hot extrusion should be summarized as follows. Firstly, the hot extrusion segments the coarse secondary phases into small ones and redistributes them. Secondarily, the hot extrusion results in the elongation and recrystallization, which results in the refinement of the microstructure. However, the difference between the one-pass hot extrusion and two-pass hot extrusion is the rheology behavior of the alloy at different conditions. According to previous research [28,29], the strength of the Mg-based alloy would decrease greatly during the deformation above $400{ }^{\circ} \mathrm{C}$. In the present research, the one-pass hot extrusion is carried out at $460{ }^{\circ} \mathrm{C}$ and the softened alloy is easy to deform along the extrusion mold. Due to the crystal orientation difference, the grains easy to deform along the extrusion direction are elongated while the others are apt to adjust the crystal orientation by crystal torsion. Then, the region adjacent to the grain boundary experiences more deformation during the torsion, which promotes the recrystallization and produces the fine grains. Simultaneously, the coarse secondary phase along grain boundary is broken and enveloped by the recrystallized grains. Unfortunately, the coarse original microstructure, relative high extrusion temperature and small extrusion ratio restricted the microstructure optimization. Additionally, there are still many coarse elongated grains and linearly distributed secondary phases, which 
are harmful to the ductility. However, the one-pass hot extrusion also promotes the crystal plane preference along $\{10 \overline{1} 1\},\{10 \overline{1} 2\}$ and $\{10 \overline{1} 3\}$, which benefits the initiation of twinning $[30,31]$. Therefore, it can be found that there is a lot of tensile twinning in one-pass hot extrusion during the tensile test. Though the twinning could help the deformation, its boundary also provides the crack initiation site. Therefore, the one-pass hot extrusion improves obviously the strength but is of almost no help to the ductility. The two-pass hot extrusion obviously changed the situation. It refines the grain and secondary phase further. Moreover, the refined secondary phases were redistributed more uniformly. Such a microstructure evolution should be mainly attributed to the pinning effect by the linearly distributed secondary phase during the hot extrusion. These linearly distributed secondary phases segment the coarse elongated grains and promote the recrystallization. In turn, the deformed matrix also helps the refinement of the secondary phase. Then, the two-pass hot extruded alloy with a well optimized microstructure obtains the highest ductility and strength simultaneously.

\section{Conclusions}

In the present research, the $\mathrm{Mg}-4 \mathrm{Zn}-1.2 \mathrm{Y}-0.8 \mathrm{Nd}$ alloy was heat treated and processed by one-pass or two-pass hot extrusion. The microstructure evolution and mechanical properties were investigated, and some conclusions can be drawn.

(1) In the heat-treated alloy, the semi-continuously distributed $\mathrm{W}-\mathrm{Mg}_{3} \mathrm{Zn}_{3} \mathrm{Y}_{2}$ phases form the skeleton structure which separates the $\alpha-\mathrm{Mg}$ matrix into a dual-size grain structure. In addition, the $\mathrm{Mg}_{24} \mathrm{Y}_{5}, \mathrm{Mg}_{41} \mathrm{Nd}_{5}$ and $\mathrm{Y}_{2} \mathrm{O}_{3}$ phases were also observed in the heat-treated alloy. Moreover, it can be found that the $\mathrm{Mg}_{24} \mathrm{Y}_{5}$ phase has orientation relationships with the $\alpha-\mathrm{Mg}$ matrix of $[111]_{\mathrm{Mg} 24 \mathrm{Y} 5} / /[0001]_{\alpha-\mathrm{Mg}}$ and $(10 \overline{1})_{\mathrm{Mg} 24 \mathrm{Y}_{5}} / /(10 \overline{10})_{\alpha-\mathrm{Mg}}$ and the $\mathrm{Mg}_{41} \mathrm{Nd}_{5}$ phase has an orientation relationship with the $\alpha-\mathrm{Mg}$ matrix of $[001]_{\mathrm{Mg} 41 \mathrm{Nd} 5} / /[0001]_{\alpha-\mathrm{Mg}}$.

(2) One-pass hot extrusion segments the secondary phases and refines the $\alpha-\mathrm{Mg}$ matrix. Due to the moderate recrystallization and crystal orientation difference, the coarse elongated grains surrounded by the fine recrystallized grain and secondary phase are the main feature of the one-pass hot extruded alloy. Furthermore, the secondary phases exhibit the linear distribution along the extrusion direction.

(3) Two-pass hot extrusion refines the secondary phase and matrix further, which produces the ultrafine $\alpha$-Mg matrix with a uniform grain size. Additionally, the two-pass hot extruded alloy possesses well redistributed secondary phases and crystal orientation preference apt for slipping initiation.

(4) Due to the microstructure optimization by hot extrusion, the ductility and strength of the $\mathrm{Mg}-\mathrm{Zn}-\mathrm{Y}-\mathrm{Nd}$ alloy were well improved, especially the two-pass hot extruded alloy which obtains a significant increase in strength and ductility simultaneously.

Author Contributions: Conceptualization, L.S.; methodology, H.Z. and T.X.; formal analysis, B.D.; investigation, X.Z.; writing-original draft preparation, L.S.; writing-review and editing, L.S. and Y.Z.; supervision, Y.Z. and T.X.; funding acquisition, L.S. All authors have read and agreed to the published version of the manuscript.

Funding: The authors are grateful to the National Key Research and Development Program of China (2018YFC1106702), Natural Science Foundation of Guangdong Province, China (2018A030313950 and 2020A151501305) the Natural Science Basic Research Plan in Shaanxi Province of China (2021JM-403), Shenzhen Basic Research Project (JCYJ20170815153143221, JCYJ20200109144608205 and JCYJ20170306141749970) and the Xi'an Science and Technology Plan Project (2020KJRC0100) for financial support.

Institutional Review Board Statement: Not applicable.

Informed Consent Statement: Not applicable.

Data Availability Statement: Data available upon request from the corresponding author.

Conflicts of Interest: The authors declare no conflict of interest. 


\section{References}

1. Wang, J.; Xu, J.; Wang, X.; Sheng, L.; Zheng, L.; Song, B.; Wu, G.; Zhang, R.; Yao, H.; Zheng, N.; et al. Magnesium-pretreated periosteum for promoting bone-tendon healing after anterior cruciate ligament reconstruction. Biomaterials 2020, 268, 120576. [CrossRef]

2. Pulido-González, N.; Torres, B.; Rodrigo, P.; Hort, N.; Rams, J. Microstructural, mechanical and corrosion characterization of an as-cast Mg-3Zn-0.4Ca alloy for biomedical applications. J. Magnes. Alloys 2020, 8, 510-522. [CrossRef]

3. Wang, S.D.; Xu, D.K.; Wang, B.J.; Sheng, L.Y.; Han, E.H.; Dong, C. Effect of solution treatment on stress corrosion cracking behavior of an as-forged Mg-Zn-Y-Zr alloy. Sci. Rep. 2016, 6, 29471. [CrossRef]

4. Du, B.; Hu, Z.; Wang, J.; Sheng, L.; Zhao, H.; Zheng, Y.; Xi, T. Effect of extrusion process on the mechanical and in vitro degradation performance of a biomedical Mg-Zn-Y-Nd alloy. Bioact. Mater. 2020, 5, 219-227. [CrossRef]

5. Bowen, P.K.; Drelich, J.; Goldman, J. Zinc Exhibits Ideal Physiological Corrosion Behavior for Bioabsorbable Stents. Adv. Mater. 2013, 25, 2577-2582. [CrossRef] [PubMed]

6. Němec, M.; Jäger, A.; Tesař, K.; Gärtnerová, V. Influence of alloying element Zn on the microstructural, mechanical and corrosion properties of binary Mg-Zn alloys after severe plastic deformation. Mater. Charact. 2017, 134, 69-75. [CrossRef]

7. Ye, Z.J.; Teng, X.Y.; Lou, G.; Zhou, G.R.; Leng, J.F. Microstructure and mechanical properties of Mg-Zn-Y alloy containing LPSO phase and I-phase. Mater. Res. Express 2017, 4, 086502. [CrossRef]

8. Wang, S.D.; Xu, D.K.; Wang, B.J.; Sheng, L.Y.; Qiao, Y.X.; Han, E.H.; Dong, C. Influence of phase dissolution and hydrogen absorption on the stress corrosion cracking behavior of Mg-7\%Gd-5\%Y-1\%Nd-0.5\%Zr alloy in 3.5 wt.\% NaCl solution. Corros. Sci. 2018, 142, 185-200. [CrossRef]

9. Wang, B.J.; Xu, D.K.; Wang, S.D.; Sheng, L.Y.; Zeng, R.C.; Han, E. Influence of solution treatment on the corrosion fatigue behavior of an as-forged Mg-Zn-Y-Zr alloy. Int. J. Fatigue 2019, 120, 46-55. [CrossRef]

10. Du, B.; Hu, Z.; Sheng, L.; Xu, D.; Zheng, Y.; Xi, T. Influence of Zn Content on Microstructure and Tensile Properties of Mg-Zn-Y-Nd Alloy. Acta Metall. Sin. Engl. 2018, 31,351-361. [CrossRef]

11. Wang, B.; Xu, K.; Xu, D.; Cai, X.; Qiao, Y.; Sheng, L. Anisotropic corrosion behavior of hot-rolled Mg-8 wt.\%Li alloy. J. Mater. Sci. Technol. 2020, 53, 102-111. [CrossRef]

12. Du, B.N.; Hu, Z.Y.; Sheng, L.Y.; Xu, D.K.; Qiao, Y.X.; Wang, B.J.; Wang, J.; Zheng, Y.F.; Xi, T.F. Microstructural characteristics and mechanical properties of the hot extruded Mg-Zn-Y-Nd alloys. J. Mater. Sci. Technol. 2021, 60, 44-55. [CrossRef]

13. Kang, Y.; Du, B.; Li, Y.; Wang, B.; Sheng, L.; Shao, L.; Zheng, Y.; Xi, T. Optimizing mechanical property and cytocompatibility of the biodegradable Mg-Zn-Y-Nd alloy by hot extrusion and heat treatment. J. Mater. Sci. Technol. 2018, 35, 6-18. [CrossRef]

14. Du, B.N.; Xiao, Z.P.; Qiao, Y.X.; Zheng, L.; Yu, B.Y.; Xu, D.K.; Sheng, L.Y. Optimization of microstructure and mechanical property of a Mg-Zn-Y-Nd alloy by extrusion process. J. Alloys Compd. 2018, 775, 990-1001. [CrossRef]

15. Jiang, H.; Qiao, X.; Xu, C.; Kamado, S.; Wu, K.; Zheng, M. Influence of size and distribution of W phase on strength and ductility of high strength Mg-5.1Zn-3.2Y-0.4Zr-0.4Ca alloy processed by indirect extrusion. J. Mater. Sci. Technol. 2018, 34, 277-283. [CrossRef]

16. Tian, Y.; Huang, H.; Yuan, G.; Ding, W. Microstructure evolution and mechanical properties of quasicrystal-reinforced Mg-Zn-Gd alloy processed by cyclic extrusion and compression. J. Alloys Compd. 2015, 626, 42-48. [CrossRef]

17. Li, Q.; Wang, Q.; Wang, Y.; Zeng, X.; Ding, W. Effect of Nd and Y addition on microstructure and mechanical properties of as-cast Mg-Zn-Zr alloy. J. Alloys Compd. 2017, 427, 115-123. [CrossRef]

18. Zengin, H.; Turen, Y. Effect of $\mathrm{Y}$ addition on microstructure and corrosion behavior of extruded $\mathrm{Mg}-\mathrm{Zn}-\mathrm{Nd}-\mathrm{Zr}$ alloy. J. Magnes. Alloys 2020, 8, 640-653. [CrossRef]

19. Sheng, L.Y.; Du, B.N.; Wang, B.J.; Xu, D.K.; Lai, C.; Gao, Y.; Xi, T.F. Hot Extrusion Effect on the Microstructure and Mechanical Properties of a Mg-Y-Nd-Zr Alloy. Strength Mater. 2018, 50, 184-192. [CrossRef]

20. Sheng, L.Y.; Guo, J.T.; Tian, Y.X.; Zhou, L.Z.; Ye, H.Q. Microstructure and mechanical properties of rapidly solidified NiAl-Cr (Mo) eutectic alloy doped with trace Dy. J. Alloys Compd. 2009, 475, 730-734. [CrossRef]

21. Wu, L.; Li, H. Effect of selective oxidation on corrosion behavior of Mg-Gd-Y-Zn-Zr alloy. Corros. Sci. 2018, 142, 238-248. [CrossRef]

22. Zhang, Y.; Du, K.; Zhang, W.; Du, B.; Qi, D.; Li, W.; Song, M.; Sheng, L.; Ye, H. Shear deformation determined by short-range configuration of atoms in topologically close-packed crystal. Acta Mater. 2019, 179, 396-405. [CrossRef]

23. Yu, H.; Xin, Y.; Wang, M.; Liu, Q. Hall-Petch relationship in Mg alloys: A review. J. Mater. Sci. Technol. 2018, 34, 248-256. [CrossRef]

24. Wang, B.; Xu, D.; Sheng, L.; Han, E.; Sun, J. Deformation and fracture mechanisms of an annealing-tailored "bimodal" grainstructured Mg alloy. J. Mater. Sci. Technol. 2019, 35, 2423-2429. [CrossRef]

25. Chapuis, A.; Driver, J.H. Temperature dependency of slip and twinning in plane strain compressed magnesium single crystals. Acta Mater. 2011, 59, 1986-1994. [CrossRef]

26. Jin, Z.Z.; Cheng, X.M.; Zha, M.; Rong, J.; Zhang, H.; Wang, J.G.; Wang, C.; Li, Z.G.; Wang, H.Y. Effects of Mg17Al12 second phase particles on twinning-induced recrystallization behavior in Mg-Al-Zn alloys during gradient hot rolling. J. Mater. Sci. Technol. 2019, 35, 2017-2026. [CrossRef]

27. Zhao, H.D.; Qin, G.W.; Ren, Y.P.; Pei, W.L.; Chen, D.; Guo, Y. The maximum solubility of Y in $\alpha$-Mg and composition ranges of Mg24Y5-x and Mg2Y1-x intermetallic phases in Mg-Y binary system. J. Alloys Compd. 2011, 509, 627-631. [CrossRef] 
28. Liu, X.; Chen, R.; Han, E. High temperature deformations of Mg-Y-Nd alloys fabricated by different routes. Mater. Sci. Eng. A 2008, 497, 326-332. [CrossRef]

29. Asqardoust, S.; Zarei-Hanzaki, A.; Fatemi, S.M.; Moradjoy-Hamedani, M. High temperature deformation behavior and microstructural evolutions of a high Zr containing WE magnesium alloy. J. Alloys Compd. 2016, 669, 108-116. [CrossRef]

30. Liu, Q. Research progress on plastic deformation mechanism of Mg alloy. Acta Metall. Sin. 2010, 46, 1458-1472. [CrossRef]

31. Sheng, L.Y.; Du, B.N.; Hu, Z.Y.; Qiao, Y.X.; Xiao, Z.P.; Wang, B.J.; Xu, D.K.; Zheng, Y.F.; Xi, T.F. Effects of annealing treatment on microstructure and tensile behavior of the Mg-Zn-Y-Nd alloy. J. Magnes. Alloys 2020, 8, 601-613. [CrossRef] 